\title{
Truth-telling and patient diagnoses
}

Robert J Sullivan, Lawrence W Menapace and Royce M White Marist College, Poughkeepsie, New York, USA

\section{Abstract}

How do physicians handle informing patients of their diagnoses and how much information do patients really want? How do registered nurses view both sides of this question?

Three questionnaires were constructed and administered in a mid-size hospital in New York state. Physicians and nurses underestimate the number of patients who want detailed information. Patients who earn more than average, have a college education, and who are under age 60 are more likely to want information, and state that their physician should give it to them. Only $42 \%$ of physicians state that patients want a detailed description of their diagnosis and treatment options. Physicians educated outside the USA appeared to be more likely to change their criteria for informing patients and, along with American-educated nurses, were more willing to participate in formal discussions of the issue.

Physicians should comply with the wishes of patients for information and include them in the team deciding on diagnosis and treatment.

(Fournal of Medical Ethics 2001;27:192-197)

Keywords: Truth-telling; diagnoses; informed consent; prognosis

\section{Introduction}

Truth-telling in medicine is a broad area and often encompasses several ethical issues. These issues include the right of patients or their families to receive information about their diagnosis and illness. The physician, on the other hand, must balance his or her obligation to tell the truth against the imperative of "do no harm". Questions often arise concerning how much truth to tell. When, if ever, is a physician justified in withholding information? Can too much information be harmful? These conflicts between benevolent paternalism on the part of the physician and an increasing interest on the part of the patient to preserve autonomy are not easily resolved.

This paper describes our research into the area of truth-telling. Our goals were to gather information about what patients want to be told about their illnesses. We were also interested in exploring the standards used by physicians when making decisions about information given to patients. Our third goal was to investigate the opinions and observations of nurses on these topics. Previous studies indicate that the majority of patients want information about their diagnoses. ${ }^{1}$ Data are also available concerning the attitudes and policies of physicians. ${ }^{23}$ These studies were done several years ago and need to be updated.

\section{Methods}

Three research questions were used in this project. They were:

1. How much information do patients want to know concerning their diagnosis and treatment?

2. What individual policies are used by physicians when deciding to inform patients of their diagnosis and treatment options?

3. Do registered nurses feel that the situation is handled adequately?

Three populations were examined in this study, patients, physicians and nurses. The administration of an acute care hospital agreed to assist us. This gave us access to the three groups in the same facility. The hospital is a 295-bed, acute-care facility located in the mid-Hudson valley of New York state.

The surveys consisted of three sets of questionnaires with covering letters explaining the project and the participant's part in it. One set was made available to patients visiting the same dayoutpatient facility or arriving for pre-admission workup at the hospital. Ten thousand and seventyseven patients came through this department during this period. Questionnaires were available at the clerk's desk to adult patients over a three-month period. Participation was voluntary. No attempt was made to identify any patient. It was made clear in the covering letter that the survey was not connected to the patient's reason for visiting the hospital or to his or her own diagnosis. Surveys were used in the study only if they had been completely filled out.

A second questionnaire was given to physicians with admitting privileges to the hospital. The surveys were distributed and collected at medical division meetings over the course of a year. As with patients, no attempt was made to identify individual physicians. The physicians were asked to address the problem of informing a patient with a poor prognosis.

The third questionnaire was given to the registered nurses on the staff of the hospital. As with the other two components of the project, this survey was voluntary and anonymous. Participation of the professional nursing staff was judged vital to the project. Nurses must deal with the consequences of physician policies concerning this topic, with both the patient and with his family. The nursing questionnaire was used as a control on the patient and physician data. Were nurses seeing consistencies or inconsistencies between what 
patients wanted and what policies physicians were following?

Data was examined statistically for consensus within each group and for similarities in consensus between the three sets of questionnaires. Data were also examined for possible correlations between demographic information on each population and the possible consensus determined for each group.

\section{Results}

Results are presented in tabular format, listing common questions for patients, physicians and nurses. Descriptive percentages are given along with some relationships between demographics and opinion responses. Statistical significance of these relationships was tested by the $\chi$-squared statistic and logistic regression analysis. The answers to selected questions for the three groups were then compared to each other (z-tests for the difference between two proportions).

\section{Patients}

Results for those patients choosing to participate can be seen in table 1 . The vast majority of patients stated that they want to know about their condition $(99 \%)$. They also thought that physicians had an obligation to inform patients of their condition $(99 \%)$, and they would want to be told if they had a life-threatening illness (97\%).
Most of the participating patients (95\%) also agreed that if patients are informed of their illness and are active in their treatment, the course of the disease is easier and the outcome is better. However, only $72 \%$ personally would want to be told all of the details themselves. A higher percentage $(85 \%)$ would want their family members to be informed of their exact condition.

There was a statistically significant relationship between age, income and amount of education, when compared with the amount of information a patient wants to be told by physicians. A higher percentage of those with higher income want to be told details. Of those participating patients making $\$ 41,000$ or more per year, $81 \%$ wanted details, compared to a range of from only $62 \%$ to $71 \%$ of those in the smaller income categories, $(p=.06)$.

If patients were over 60 years of age, only $61 \%$ wanted to be told all details, compared to a range of from $73 \%$ to $82 \%$ of younger age groups $(p=.02)$. Those with a college education or more had a higher percentage $(84 \%)$ wanting to be told details compared to $62 \%$ of those with high school or less $(\mathrm{p}=.00007)$.

The above relationship between age and wanting to be told may be due to the patient's education rather than to age as such because age and education were highly related to each other $(\mathrm{p}=.00001)$. As one might expect, a higher percentage (range

Table 1 Responses for patients (and on similar questions for physicians, and nurses)

\begin{tabular}{|c|c|c|c|c|}
\hline Question & Answer & Patient & Physician & Nurse \\
\hline Patients have right to know about their condition & Yes & $99 \%$ & & $99 \%$ \\
\hline Physicians have obligation to inform patients of condition & Yes & $99 \%$ & & $100 \%$ \\
\hline I want to be told of serious, life-threatening diagnosis & Yes & $97 \%$ & & \\
\hline \multirow[t]{3}{*}{ Told how much on illness and treatments } & All details & $62 \%$ & $39 \%$ & $29 \%$ \\
\hline & General terms & 28 & 57 & 60 \\
\hline & Both (= details) & 10 & 3 & 11 \\
\hline \multirow[t]{2}{*}{ Want family informed of exact condition } & Yes & $85 \%$ & $58 \%$ & $33 \%$ \\
\hline & Sometimes & & 40 & 67 \\
\hline \multirow[t]{2}{*}{ If patient is informed and active participant, better outcome results } & Yes & $95 \%$ & $76 \%$ & $83 \%$ \\
\hline & Sometimes & & 23 & 17 \\
\hline \multirow[t]{5}{*}{ Patient age } & $18-30$ & $11 \%$ & & \\
\hline & $31-40$ & 16 & & \\
\hline & $41-50$ & 23 & & \\
\hline & $51-60$ & 17 & & \\
\hline & Over 60 & 33 & & \\
\hline \multirow[t]{5}{*}{ Patient income } & Below $\$ 20000$ & $17 \%$ & & \\
\hline & $\$ 21000-40000$ & 35 & & \\
\hline & $\$ 41000-60000$ & 18 & & \\
\hline & Over 60000 & 18 & & \\
\hline & No answer & 12 & & \\
\hline \multirow[t]{5}{*}{ Patient education } & Grade school & $4 \%$ & & \\
\hline & High school & 50 & & \\
\hline & College & 32 & & \\
\hline & Postgraduate & 11 & & \\
\hline & No answer & 3 & & \\
\hline
\end{tabular}

$\mathrm{N}=337$ patients with percentages calculated on 326 to 331 who answered any given question. $\mathrm{N}=72$ physicians with percentages calculated on 66 to 71 .

$\mathrm{N}=66$ nurses with percentages calculated on 60 to 66 
from $67 \%$ to $69 \%$ ) of the various older age categories had only a high school education or less, compared to a range of from $39 \%$ to $45 \%$ for the younger age categories with only a high school education. However, when the relationship between education and wanting to be told details was examined for each age category (multivariate cross tabulation), the same trend appeared for each age, that is: those with more education want to be told more. The role of education was confirmed by a logistic regression analysis. Education level was the first variable entered into the prediction equation $(p<.001)$ and resulted in an estimated odds ratio of 3.1. Knowing a patient's educational level increases the odds of knowing whether a patient wants details about the illness by 3.1 times. Adding a patient's age or income category did not increase prediction at the $\mathrm{p}<.05$ level, and thus they were not added to the regression equation.

There was no significant relationship between the number of physician contacts in the last year and wanting to be told all details. There was a statistically significant relationship $(\mathrm{p}=.0001)$ between wanting family members to know one's exact condition and patient age. Of those over 60 years old, $94 \%$ want family to know details, compared to only $68 \%$ of those aged 18 to 30 Intermediate ages had intermediate results ranging from $73 \%$ to $88 \%$. Logistic regression analysis confirmed that neither education nor income were related (not significant at $\mathrm{p}<.05$ ) to this variable.

\section{Physicians}

Approximately $90 \%$ of the physicians attending department meetings completed the questionnaire. This represents $75 \%$ of the physicians at the facility. Results for questions asked of both physicians and nurses are in tables 1 and 2. Most physicians reported that they inform patients of the major implications of their diagnosis and treatment; $24 \%$ said they inform patients 50 to $90 \%$ of the time; $39 \%$ said 95 to $99 \%$ of the time, and $37 \%$ said they inform $100 \%$ of the time. There was no relationship between the answer to this question and physician age or country of medical school.

Only $42 \%$ of physicians said patients want to be told all details about a serious illness. Fifty-seven per cent said patients want to be told only in general terms and one per cent said patients want no information. There was no relationship between the answer to this question and the physician's age or country of medical school. On a related question, $58 \%$ of physicians stated that patients wanted their family informed of the details compared to $40 \%$ who said that this was true only sometimes. Thus, both physicians and patients indicated a higher percentage of patients wanted family informed than wanted to be informed themselves.

There was a difference among the specialties in the belief that patients want to be told all details. The groups that were more likely to say that patients want details explained to them (over half in each group) were from surgery, pulmonary medicine, gastroenterology and neuropsychology. For the other physician specialty groups, half or less thought patients want all details.

Younger physicians were significantly more likely $(\mathrm{p}=.07)$ to have had formal training in ethics compared to those who are older. Of those aged 29 to $39,67 \%$ said they had formal training in ethics, compared to $34 \%$ of those aged 40 to 49 , and $32 \%$ if age 50 and above.

A relationship was found between graduating from a US versus a non-US medical school in respect of the answers to three questions. Of those graduating from US medical schools, $74 \%$ agreed that an informed patient is a better patient, compared to $96 \%$ of those from non-US schools ( $p$ $=.04$ ). Only $22 \%$ of US school graduates said their strategy about informing patients is probably or certainly likely to change, compared to $52 \%$ of non-US school graduates $(\mathrm{p}=.02)$.

Only $42 \%$ of US school graduates were interested in participating in structured discussions of this subject compared to $79 \%$ of non-US graduates $(\mathrm{p}=.01)$.

\section{REGISTERED NURSES}

Responses to questions for nurses are in tables 1,2 and 3 . An adequate number of responses were obtained from nurses to evaluate the research questions of the study. Nurses also thought that patients have a right to be told everything concerning their illness $(99 \%)$ and that physicians have an obligation to inform the patient $(100 \%)$. However, $60 \%$ believed that patients only expect general explanations of their problems. Only $46 \%$ of nurses said they had received formal training in medical ethics, and $79 \%$ were interested in participating in structured discussions of medical ethics. There was a relationship $(p=.02)$ between the age of a nurse and interest in participating in such discussions. Only $63 \%$ of nurses age 21 to 40 want discussion compared to $90 \%$ of nurses age 41 to 57 .

\section{Differences in views among groups}

There was a statistically significant difference $(\mathrm{p}<$ .0001) between the percentage of patients who want to be told all details $(72 \%)$ and of nurses who said patients want to be told all details (40\%) (z-test for the difference between two proportions). There was also a difference between patients $(72 \%)$ and physicians $(42 \%)$ concerning details $(\mathrm{p}<.0001)$. There was no difference between nurses and physicians on this question.

Nurses and physicians did not agree on whether patients want family notified of details of their illness. Whereas only $33 \%$ of nurses said this was always true, $58 \%$ of physicians thought it was always true $(p<.001)$. On this question, more nurses stated that patients sometimes wanted family informed $(67 \%)$ compared to physicians $(40 \%)$. Very few of either group said patients did not want their family told.

When asked if they would be interested in participating in structured discussions of this subject, $79 \%$ of nurses answered "Yes" compared to only $52 \%$ of physicians, $\mathrm{p}<.001$. 
Table 2 Additional responses of physicians (and on similar questions for nurses)

\begin{tabular}{|c|c|c|c|c|c|}
\hline Question & Answer & Physician & & Nurse & \\
\hline $\begin{array}{l}\text { Informs patients of major implications of diagnosis } \\
\text { and treatment }\end{array}$ & $\begin{array}{l}50-85 \% \text { of time } \\
90 \% \\
95 \% \\
97-99 \% \\
100 \% \text { of time }\end{array}$ & $\begin{array}{l}8.5 \% \\
15.5 \\
19.7 \\
19.7 \\
36.6\end{array}$ & & & \\
\hline How often make exceptions to rule on informing & $\begin{array}{l}0 \% \text { (never) } \\
1 \% \text { of time } \\
2-5 \% \\
10 \% \\
15-95 \% \text { of time }\end{array}$ & $\begin{array}{l}36.8 \% \\
14.7 \\
22.0 \\
17.6 \\
8.8\end{array}$ & & & \\
\hline $\begin{array}{l}\text { Factors most commonly included in top } 5 \text { which } \\
\text { may influence decision to inform patient }\end{array}$ & $\begin{array}{l}\text { Emotional stability } \\
\text { Improve compliance } \\
\text { Age } \\
\text { Patient requests diagnosis } \\
\text { Prognosis } \\
\text { Acceptance of therapy } \\
\text { Medical sophistication } \\
\text { Harmful to outcome } \\
\text { Length of survival }\end{array}$ & $\begin{array}{l}\text { Top 5/ } \\
51 \% \\
44 \\
33 \\
33 \\
28 \\
24 \\
24 \\
19 \\
14\end{array}$ & $\begin{array}{l}\text { First } \\
11 \% \\
4 \\
24 \\
8 \\
3 \\
6 \\
4 \\
3 \\
1\end{array}$ & $\begin{array}{l}\text { Top } 5 / \\
74 \% \\
53 \\
30 \\
62 \\
45 \\
47 \\
9 \\
18 \\
26\end{array}$ & $\begin{array}{l}\text { First } \\
30 \% \\
6 \\
15 \\
20 \\
2 \\
5 \\
2 \\
2 \\
3\end{array}$ \\
\hline $\begin{array}{l}\text { How did you acquire strategy for dealing with } \\
\text { informing patients (\% ranking in top } 7 \text { ) }\end{array}$ & $\begin{array}{l}\text { Other } \\
\text { Clinical training } \\
\text { Medical school } \\
\text { Personal factors } \\
\text { Experience } \\
\text { Family, friends } \\
\text { Commonly accepted }\end{array}$ & $\begin{array}{l}45.8 \% \\
13.9 \\
12.5 \\
8.3 \\
8.3 \\
2.8 \\
1.4\end{array}$ & & & \\
\hline Received formal training in medical ethics & Yes & $41 \%$ & & $46 \%$ & \\
\hline $\begin{array}{l}\text { How likely is strategy of informing patients to } \\
\text { change }\end{array}$ & $\begin{array}{l}\text { No possibility } \\
\text { Very unlikely } \\
\text { Unlikely } \\
\text { Probably } \\
\text { Certainly }\end{array}$ & $\begin{array}{l}9 \% \\
30 \\
30 \\
26 \\
6\end{array}$ & & & \\
\hline $\begin{array}{l}\text { Interested in participating in structured discussion } \\
\text { of this topic }\end{array}$ & Yes & $52 \%$ & & $79 \%$ & \\
\hline $\begin{array}{l}\text { If you were a patient, would you want to be fully } \\
\text { informed }\end{array}$ & Yes & $100 \%$ & & $100 \%$ & \\
\hline $\begin{array}{l}\text { When patient's death is expected outcome, you feel } \\
\text { that (ranked first) }\end{array}$ & $\begin{array}{l}\text { Best therapeutic alternatives have been } \\
\text { followed } \\
\text { Medical profession has failed this patient } \\
\text { This is a personal failure } \\
\text { None ranked }\end{array}$ & $\begin{array}{l}86 \% \\
2 \\
4 \\
8\end{array}$ & & & \\
\hline Medical specialty (percentage of sample) & $\begin{array}{l}\text { Internal medicine } \\
\text { Surgery } \\
\text { Neuropsychology } \\
\text { Family practice } \\
\text { Plastic surgery } \\
\text { Cardiology } \\
\text { Physical medicine } \\
\text { Gastroenterology } \\
\text { Pulmonary } \\
\text { Unknown }\end{array}$ & $\begin{array}{l}19.4 \% \\
18.1 \\
9.7 \\
8.3 \\
5.6 \\
4.2 \\
4.2 \\
2.8 \\
1.4 \\
26.4\end{array}$ & & & \\
\hline Country of medical school & $\begin{array}{l}\text { USA } \\
\text { Other }\end{array}$ & $\begin{array}{l}62 \% \\
38\end{array}$ & & & \\
\hline Physician age & $\begin{array}{l}29-40 \\
41-50 \\
51-60 \\
\text { Over } 60 \\
\text { No answer }\end{array}$ & $\begin{array}{l}31 \% \\
39 \\
19 \\
3 \\
8\end{array}$ & & & \\
\hline
\end{tabular}

Note: $\mathrm{N}=72$ physicians. Percentages usually calculated based on number answering question, ranging from 66 to 71 for opinion (non-demographic) questions. 
Table 3 Additional responses of nurses only

\begin{tabular}{lll}
\hline Question & Answer & Nurses \\
\hline $\begin{array}{c}\text { Do nurses favour patients with poor } \\
\text { prognosis being informed }\end{array}$ & Yes & $97 \%$ \\
If prognosis is poor have you found & No opinion & 3 \\
physicians & Inform & $31 \%$ \\
& Do not inform & 2 \\
& No consistent policy & 67 \\
If prognosis is poor, how often are you in & Frequently & $8 \%$ \\
conflict with physician re: informing & Sometimes & 79 \\
patient & Never & 13 \\
Nurse's specialty area & Medical & $22 \%$ \\
& Surgical & 25 \\
& Critical care & 33 \\
Nurse's education & Emergency & 20 \\
& Diploma & $29 \%$ \\
& AS & 43 \\
& BSN & 22 \\
Nurse's age & Masters & 6 \\
& & $7 \%$ \\
& $21-30$ & 35 \\
& $31-40$ & 32 \\
& $41-50$ & 12 \\
& $51-57$ & 14 \\
\hline
\end{tabular}

Note: $\mathrm{N}=66$ nurses. Percentages usually calculated based on number of nurses answering question, ranging from 60 to 66 .

There was not a significant difference between the percentage of nurses $(83 \%)$ compared to physicians $(76 \%)$ who thought that patients as active participants produce an easier course of treatment and better outcome.

\section{Discussion}

The percentage of patients participating in the study is low and may not represent the patient population as a whole. Patients who participated consistently responded that they have a right to know their condition, that they expect physicians to inform them and that they want to be informed if they have a life-threatening illness. Similar results have been reported for patients with serious illness ${ }^{4}$ and, specifically, in patients with ovarian cancer. ${ }^{5}$ In every age group, the more education patients have, the more they wish to be told. This description applies whether the patients see their doctor infrequently or have a chronic illness necessitating frequent physician visits. The older patients are, the more they want their family to know details of their condition. A recent study in Japan also found education to be a determining factor. ${ }^{6}$

About a quarter of the physicians state that they inform their patients between $50 \%$ and $90 \%$ of the time. Over half of the physicians inform their patients in general terms of their illnesses but not in detail. Less than half of the physician participants in the study feel that patients want to be told all the details of their condition. These findings are in contrast to two studies that found $98 \%$ and $90 \%$ of physicians gave cancer patients specific information about their condition. ${ }^{78}$ All physicians participating in this study wished to be informed of a life-threatening illness if they were the patient. A similar study of Alzheimer's disease found that $71 \%$ of those physicians wanted to be informed. ${ }^{9}$ The physicians in that study informed their patients about $40 \%$ of the time. In the current study, internal medicine and family practice are two specialties which were also in the earlier study.

Somewhat more than half of the physicians say that patients want their families informed of the details of their condition. Physicians and nurses both comment that this depends on the patients and their intrafamily relationships. One physician commented that he communicates to families "a majority of the time when (the patient is) married, less often when young, single, divorced, or separated". It should be noted that patients appear to want someone to know the details of their illness, even when they decline details themselves.

One physician noted that he found it difficult to rank-order any factors that would affect his policy of informing patients. Several others commented that their deciding factor was the patient's request not to be told. Other factors mentioned were the golden rule and intuition. One nurse commented that "some physicians have a difficult time telling a patient with a poor prognosis information concerning their condition". More non-US than USeducated physicians indicated a willingness to change their policies and to participate in structured discussions of this aspect of medical ethics. A doctor commented that "ethically I must inform all patients, legally I would be insane not to"; another said that "regardless of the factors mentioned, patients deserve to know as much as they want".

Physicians and registered nurses generally agreed on the items of the survey. They did, however, 
greatly underestimate the number of patients who want to be fully informed of their illness. Also, fewer nurses than physicians felt that patients wanted their family informed. In general, nurses were more willing to participate in formal ethical discussions than physicians.

We have demonstrated statistically significant data through this study, but what does the data imply for patient care? Greater efforts should be made to consult with patients about their condition and medical options available to them. This is supported by several other studies. ${ }^{6}{ }^{1011}$ Patients should be informed of their right to information and invited to decide about the amount of information they require in order to give a free and informed consent. Health care providers regularly underestimate the information that patients want concerning their condition. In general, the more educated a patient, the more details he requires. If the patient's family relationships allow, the physician should make a specific effort to involve the family in discussions of the patient's condition, especially if the patient is elderly. Physicians' and nurses' participation in formal discussions of these subjects may facilitate changes in physicians' policies.

We recognise that the physician has an obligation to avoid harming the patient. If the physician believes that informing the patient can cause harm, he will have a moral dilemma involving patient autonomy and possible harm. We feel that violating patient autonomy is a serious matter and should be done cautiously and rarely. Paternalistic decisions made by a physician must be justified and made on medical grounds only. Decisions made to avoid possible social or psychological harm to the patient are beyond the scope of medical expertise.

Perhaps the comment of one physician sums up the feelings of many participants in this study: "I'm not the God of this patient, just a technician with an education, despite society's view of doctors' compassion, who does the best he can".

Robert F Sullivan, PhD, MT(ASCP), is Associate Professor of Medical Laboratory Science, Marist College,
Poughkeepsie, New York, USA. Lawrence Menapace, $\mathrm{PhD}$, is Associate Professor of Chemistry, Marist College, Poughkeepsie and Royce M White, PhD, is Associate Professor of Psychology, Marist College, Poughkeepsie.

\section{References}

1 Aitken-Swan T, Easson EC. Reactions of cancer patients on being told their diagnoses. British Medical fournal, 1959;5124:779-83. McIntosh J. Patients' awareness and desire
for information about diagnosed but underscored malignant disease. Lancet, 1976;7:300-3. Kelly WD, Friesen SR. Do cancer patients want to be told. Surgery.1950;27:822-6.

2 Oken D. What to tell cancer patients. Fournal of the American Medical Association. 1961;175:1120-28. Veatch R. Death, dying and the biological revolutio Press, 1976: 229-38.

3 Cullen S, Klein M. Respect for patients, physicians, and the truth, In: Munson R, ed. Intervention and reflections: basic issues in medical ethics [6th ed]. Belmont, CA: Wadsworth, 1999: 43542 .

4 Mansell D, Poses RM, Kazis L, Duefield CA. Clinical factors that influence patients' desire for participation in decisions about illness. Archives of Internal Medicine,2000;23:2991-6.

5 Stewart DE, Wong F, Cheung AM, Dancey J, Meana M, Cameron JI, et al. Information needs and decisional preferences among women with ovarian cancer. Gynecologic Oncology 2000; 77:357-61

6 Hasui C, Hayashi M, Tomoda A, Kohro M, Tanaka K, Dekio $\mathrm{F}$, et al. Patients' desire to participate in decision making in psychiatry: a questionnaire survey in Japan. Psychological Reports 2000;86:389-99.

7 Novack DB, Plumer R, Smith RL, Ochitill H, Morrow GR. Changes in physicians' attitudes toward telling the cancer patient. Fournal of the American Medical Association 1979;241: 897-900.

8 Oken D. What to tell cancer patients. Fournal of the American Medical Association 1961;175:1120-8.

9 Johnson H, Bouman WP, Pinner G. On telling the truth in Alzheimer's disease: a pilot study of current practice and attitudes. International Psychogeriatrics 2000;12:221-9.

10 Nessa J, Malterud K. Tell me what's wrong with me: a discourse analysis approach to the concept of patient discourse analysis approach to the concept of
autonomy. Fournal of Medical Ethics 1998;24:394-400.

11 Peters R. Matching physician practice style to patient informational issues and decision-making preferences: an approach to patient autonomy and medical paternalism issues in clinical practice. Archives of Family Medicine 1994;9:760-3 (special article)

\section{News and notes \\ Annual Intensive One-week Course in Medical Ethics}

The next Annual Intensive One-week Course in Medical Ethics will be held at Imperial College, London from September $17-21$.

For further information please contact: Centre for Continuing Education: email: cpd@ic.ac.uk
Centre for Continuing Education, Imperial College, Room 526, Sherfield Building, Exhibition Road, London SW7 2AZ. Telephone: +44 (0)207 594 6882; fax: +44 (0)207594 6883 